\title{
A METALINGUAGEM DE PROFESSORES DE PLE EM FORMAÇÃO: CONTRIBUIÇÕES PARA A AVALIAÇÃO DE PROFICIÊNCIA ORAL NA FORMAÇÃO DOCENTE
}

\author{
Ana Carolina Silva Mendonça DETOMINI \\ Universidade Estadual Paulista "Júlio de Mesquita Filho" - UNESP \\ Instituo de Biociências, Letras e Ciências Exatas - IBILCE \\ Pós-graduação em Estudos Linguísticos - PPGEL - UNESP/IBILCE
}

\begin{abstract}
RESUMO: Este trabalho visa contribuir com subsídios para avaliação do desempenho metalinguístico oral do professor em formação de português como língua estrangeira (PLE) no EPPLE, o Exame de Proficiência para Professores de Língua Estrangeira. Especificamente, para a formulação de questões que buscam aferir a proficiência oral do professor ao fazer o uso da própria língua alvo para explicá-la, respeitando o conhecimento das regras de comunicação e de formas da língua portuguesa que são socialmente aceitas. Para tanto, foi feito um estudo de caso em dois contextos de pesquisa em PLE da UNESP/IBILCE, campus de São José do Rio Preto: o Teletandem Institucional Integrado (TTDii), um ambiente online de ensino-aprendizagem de línguas, e o Projeto de Extensão "Português Língua Estrangeira (PLE)", cujas aulas são presenciais. A investigação, por meio dos dados coletados, propõe, mais especificamente, a i) identificar os tipos de perguntas e questões linguísticas levantadas pelos alunos em relação à língua portuguesa, enquanto aprendizes dessa língua; ii) identificar as dúvidas, levantadas pelos aprendentes de PLE, que forem mais recorrentes em ambos os contextos; iii) mapear como o professores em formação explicam as questões levantadas pelos aprendentes de PLE. Tais recorrências servirão de base para que se possibilite a criação de perguntas de avaliação para esse profissional no EPPLE, pautadas nos conceitos de avaliação que fundamentam o exame: a validade, a confiabilidade e a praticidade.
\end{abstract}

PALAVRAS-CHAVE: EPPLE; metalinguagem; PLE.

ABSTRACT: This paper aims to contribute with subsidies to evaluate the oral metalinguistic performance of the teacher who is qualifying to be a Portuguese as a foreign language (PFL) teacher in the EPPLE, the Proficiency Examination for Foreign Language Teachers. Specifically, for the formulation of questions that seek to assess the teacher's oral proficiency in making use of the target language itself to explain it, respecting the knowledge of the rules of communication and forms of the Portuguese language that are socially accepted. In order to do so, a case study was carried out in two PFL research contexts of UNESP/IBILCE, São José do Rio Preto campus: the Integrated Institutional Teletandem (TTDii), an online environment of language teaching and learning, and the Project Of Extension "Portuguese Foreign Language (PLE)", where the classes are face-to-face. The research, through the collected data, proposes, more specifically, to a) to identify the types of questions and linguistic questions raised by the students in relation to the Portuguese language, as learners of that language; $b$ ) identify the doubts raised by the PFL learners that are most recurrent in both contexts; c) mapping how the teachers explain the issues raised by PFL learners. These recurrences will serve as a basis for the creation of evaluation questions for this professional in EPPLE, based on the assessment concepts that underpin the examination: validity, reliability and practicality. KEYWORDS: EPPLE; metalanguage; PFL. 


\section{Introdução}

Estudos que permeiam a formação de professores de língua estrangeira (LE) no Brasil tem referência extensa na literatura (ALMEIDA FILHO, 1999, 2002; BAGHIN SPINELLI, 2002; BASSO, 2001; CONSOLO, 1996, 2002, 2004, 2007; CONSOLO e TEIXEIRA DA SILVA, 2007; GIL E VIEIRA-ABRAHÃO, 2008; GIMENEZ, 2002, 2003; VIEIRAABRAHÃO, 1996, 2001, 2006, 2010; entre outros), solidificando este campo como diverso e abundante em discussões e pesquisas em Linguística Aplicada (LA). Os inúmeros enfoques e metodologias dos estudos na área de formação de professores de LE revelam a complexidade do assunto e a sua importância na busca pela qualidade no ensino de línguas no contexto brasileiro.

Considerando que a língua portuguesa também pode ser estudada sob a perspectiva de língua estrangeira e, portanto, demanda equivalente esforço nessa busca por qualidade no processo de ensino e aprendizagem, pesquisas que permeiam a área de ensino e aprendizagem de português língua estrangeira (PLE) ${ }^{1}$ têm ganhado espaço e alcançado maior destaque nos últimos anos no âmbito da LA. Segundo Almeida Filho (2007), atuar na esfera de ensino de PLE significa não só "desenvolver atividades constantes, mas também estudar os processos de ensinar e aprender PLE em distintos e específicos contextos” (2007, p. 34).

Entretanto, a realidade das licenciaturas brasileiras nos mostra que a temática da formação do professor de PLE ainda gera debates e reflexões muito aquém do necessário, dificultando que esse viés da formação docente se estabeleça adequadamente no cenário acadêmico do Brasil, especialmente nas graduações. Para Kfouri-Kaneoya (2013), essa preocupação em familiarizar e capacitar o futuro professor para o ensino de português a estrangeiros se justifica pelo crescente número de oportunidades para essa atividade, tanto dentro quando fora do Brasil. Desta maneira, a formação do professor de PLE, assim como de um professor de línguas em geral, beneficia-se dos conhecimentos acerca do próprio processo de ensino e aprendizagem, acerca da natureza de uma língua não materna, e também em relação à cultura em que se insere a língua-alvo e a sua aprendizagem.

A ruptura de fronteiras linguísticas em torno da valorização de línguas não hegemônicas, como é o caso do português, vem mostrando resultados positivos, tomando-se como parâmetro o interesse de estrangeiros das mais diversas partes do mundo pelo Brasil, pela aprendizagem de PLE e pela cultura brasileira. A Universidade Estadual Paulista "Júlio de Mesquita", a UNESP, por exemplo, trabalha com uma proposta de internacionalização e recebe muitos alunos estrangeiros todos os anos, o que resulta em oportunidades para o ensino e a formação de professores de PLE em um contexto universitário onde, tradicionalmente, não se oferecia essa formação.

Por esse motivo, a tendência é que os estudos na área de PLE abranjam continuamente um número mais expressivo de pesquisadores, fortalecendo-se também em virtude do aperfeiçoamento das práticas de ensino nessa área.

A primeira motivação para a concepção desta investigação surgiu da necessidade de integração, nas pesquisas em LA, dos ambientes de formação de professores com os diferentes contextos de sala de aula. De acordo com Margonari e Silva (2007), é necessário que haja uma visão maior acerca dos desafios a serem enfrentados pelos professores para que estes possam desenvolver suas competências, uma vez que comumente é verificada a incompatibilidade de conteúdos trabalhados nos cursos de formação em relação àqueles que os professores terão que abordar em sala de aula.

Cristóvão (2005) lista como benefícios da interação entre o conhecimento teórico e prático: i) a preparação dos futuros profissionais, ii) o desenvolvimento contínuo dos educadores, iii) a melhora na aprendizagem dos alunos e iv) os avanços científicos nas pesquisas educacionais. Desta maneira, a associação desses conhecimentos poderá trazer

\footnotetext{
${ }^{1} \mathrm{O}$ termo língua estrangeira é atribuído ao português ensinado como outra língua, de acordo com a SIPLE -
} Sociedade Internacional de Português Língua Estrangeira. 
resultados positivos quando se analisar as necessidades específicas dos contextos de ensino e aprendizagem de línguas por meio de pesquisas nessa área.

Professores linguisticamente competentes nas línguas a serem por eles ensinadas constituem um aspecto primordial na formação docente. Segundo Consolo (2007), a conceituação das características da competência linguístico-comunicativa do professor e de sua proficiência para atuação em contextos de ensino de LE se torna possível por meio do mapeamento dos contextos de uso da linguagem e de seus respectivos aspectos linguísticos, evidenciando recortes representativos do domínio linguístico do professor.

No que concerne à área da avaliação, seu papel fundamental nos contextos de ensino e aprendizagem de línguas tem sido cada vez mais reconhecido por pesquisadores em LA. Seu principal objetivo é auxiliar no processo de ensino e aprendizagem, atuando não apenas como uma forma de julgar e medir o desempenho dos aprendizes, mas principalmente como um meio de reflexão, fazendo com que "todos os envolvidos no processo de ensino e aprendizagem reflitam sobre o que pode ser modificado a partir da análise de resultados avaliativos" (BUSNARDI, 2012, p. 32). Dessa maneira, deve-se pensar a avaliação como algo que permeia todo o processo de ensino e aprendizagem de línguas e não apenas como um produto que emerge ao seu final. Partindo desse pressuposto, podemos dizer que, segundo Furtoso (2011), tomar a avaliação como foco nos permite repensar também essas duas etapas.

Em outras palavras, a avaliação precisa assumir um caráter formativo, guiando o aprendiz durante todo o processo de ensino e aprendizagem, permitindo que, a partir do reconhecimento dos problemas enfrentados por ele no decorrer deste percurso, sejam feitos os reajustes necessários para que os objetivos pré-estabelecidos sejam alcançados.

Desta maneira, a avaliação da proficiência do professor de PLE se faz necessária para que se estabeleçam níveis desejados e, consequentemente, para melhorar as condições do ensino de português sob a perspectiva de língua estrangeira, uma vez que, de acordo com McNamara (2000), testes para verificar o desempenho do professor, seguindo um nível de exigências mínimo, são instituições sociais importantes.

O tema da metalinguagem, por sua vez, foi escolhido pela necessidade do professor de línguas de lançar mão de determinadas habilidades específicas no que se refere à sua linguagem em contextos de ensino e aprendizagem de línguas. Para Elder (2001), tais habilidades específicas incluem o domínio da terminologia e da metalinguagem dos conteúdos a serem ensinados, além da competência discursiva para o tratamento desses conteúdos em sala de aula. A autora define a competência discursiva do professor como "a habilidade para comunicação efetiva do conteúdo da disciplina em sala de aula" (ELDER, 2001, p. 152).

Assim, a partir de um conjunto de dados coletados de contextos representativos da realidade do curso de Licenciatura em Letras da Universidade Estadual Paulista "Júlio de Mesquita Filho" (UNESP), campus de São José do Rio Preto, o Instituto de Biociências, Letras e Ciências, Exatas (IBILCE) - a saber, o Teletandem Institucional Integrado (TTDii) e o Projeto de Extensão "Português Língua Estrangeira" - esta investigação objetiva delinear critérios de avaliação de competência metalinguística oral de professores de PLE em formação, que possam orientar, futuramente, a elaboração de questões para o EPPLE, o Exame de Proficiência para Professores de Língua Estrangeira, de modo que o exame ostente validade e confiabilidade nacionais.

Espera-se que os resultados deste trabalho se revertam para o aprimoramento da formação de professores de PLE nos cursos de Letras oferecidos no Brasil, e que também possam gerar outras contribuições para pesquisas na área de avaliação de línguas, em crescimento no país. Além disso, este tipo de pesquisa procura tornar mais acessível a interação do conhecimento produzido na teoria com a prática vivenciada pelos professores em atuação, a qual, em sua maioria, acaba se distanciando da produção de conhecimento acadêmico. 


\section{Fundamentação teórica}

Nesta seção, serão apresentados, de maneira condensada, os aportes teóricos que guiam esta pesquisa, que se baseiam em três eixos principais a serem abordados na seguinte ordem: formação de professores, metalinguagem e avaliação de proficiência oral, mais especificamente no âmbito do EPPLE.

Iniciamos pelo eixo do conhecimento sobre formação de professores de línguas e, mais especificamente, de PLE. O ensino e a aprendizagem de línguas se mostram cada vez mais relevantes no cenário mundial por causa, principalmente, das demandas da globalização. No contexto da América do Sul, sabe-se que o português e o espanhol tornaram-se línguas oficiais das relações internacionais entre os países sul-americanos. Assim, cresce o número de cursos de língua portuguesa oferecidos nos países hispano-falantes e também se torna cada vez maior o número de estudantes estrangeiros nas universidades brasileiras, os quais anseiam progredir na comunicação e compreensão do português (ALMEIDA FILHO, OEIRAS e ROCHA, 1998).

Aproximadamente, nos últimos 20 anos, houve grande expansão do ensino de PLE, uma vez que i) foi criado um exame nacional de proficiência - o Celpe-Bras ${ }^{2}$-, ii) cada vez mais profissionais estão desenvolvendo estudos nessa área, iii) há realização de eventos (como, por exemplo, os congressos e seminários da SIPLE $^{3}$ ), que publicam coletâneas e materiais didáticos, iv) além da grande demanda de profissionais que necessitaram aprender o português pelo fato de o Brasil ter sediado a Copa do Mundo de Futebol de 2014 e os Jogos Olímpicos de 2016.

Ainda que o ensino e a aprendizagem de PLE estejam se expandindo em âmbito internacional, devido às necessidades mais recentes de contato entre brasileiros e estrangeiros, tanto nos meios presenciais como nos virtuais, ainda há lacunas nos cursos de Letras, os quais não dão a devida importância à formação de professores capacitados ao ensino de PLE e PSL (português como segunda língua), visto que a formação desses professores se diferencia em demasia daquela para o ensino de português como língua materna (LM). A maioria dos cursos de Licenciatura em Letras forma professores habilitados a ensinar uma LE e a LM, não tratando do ensino de PLE.

Para Almeida Filho (2005), em relação ao nível profissional, ao campo de trabalho docente e à área de pesquisa científica,

É preciso intensificar a consciência sobre as especificidades do ensino de PLE e sobre a situação das iniciativas concertadas para o desenvolvimento dessa especialidade estratégica consubstanciadas em políticas explícitas de ensino da língua portuguesa e culturas a ela associadas, especialmente as brasileiras no nosso caso. (ALMEIDA FILHO, 2005, p. 17)

Vemos, então, que a área de PLE constitui-se como um amplo campo de estudo, ensino e pesquisa, o que torna imprescindível o desenvolvimento de recursos que auxiliem o ensino e a aprendizagem, principalmente no que concerne à necessidade de formação de professores.

Para que um professor seja caracterizado como apto a desempenhar seu papel profissional, é necessário que ele desenvolva, em sua formação, algumas competências que lhe permitam atuar satisfatoriamente. Segundo Elder (2001), as competências do professor de línguas englobam, em termos gerais, principalmente, sua competência linguísticocomunicativa, que diz respeito à habilidade do professor em utilizar a língua de maneira geral, como um falante comum, e a competência profissional, que caracteriza, além de seu

\footnotetext{
${ }^{2}$ Mais informações no site do exame: www.celpebras.inep.gov.br/inscricao

${ }^{3}$ Sociedade Internacional de Português - Língua Estrangeira.
} 
conhecimento teórico e prático, suas crenças, intuições e sentimentos que o acompanham em sua trajetória docente, sua habilidade em utilizar-se do discurso de sala de aula, diferenciandoo de um falante comum da língua em questão. Espera-se, então, que o professor utilize sua competência linguístico-comunicativa aliada à sua competência profissional, possibilitando a criação de um ambiente de aprendizagem onde a língua é adquirida pela interação entre os alunos e o professor e entre os próprios alunos.

É sabido que os diversos contextos de comunicação existentes requerem proficiências distintas, isto é, domínios linguísticos específicos. Assim, entende-se que a proficiência do professor de PLE seria estabelecida pelo domínio, inclusive, da metalinguagem necessária para o ensino da língua. Este conceito, tal como apresentado por Elder (2001), é adotado neste trabalho. Elder (op. cit.) afirma que professores de línguas necessitam de habilidades específicas que incluam o domínio da terminologia e da metalinguagem dos conteúdos a serem ensinados, além da competência discursiva para o tratamento desses conteúdos em sala de aula.

Assim sendo, além da competência profissional, o professor necessita dominar conhecimentos metalinguísticos e meta-comunicativos, ou seja, ele deverá utilizar a línguaalvo - no que diz respeito a esse estudo, o português -, para se comunicar com os aprendizes e para falar sobre a própria língua que está ensinando, o que Almeida Filho (1993) denomina de competência meta. Relaciona-se, então, à competência meta o uso apropriado da metalinguagem no ensino de PLE.

Segundo Fernandes (2011), a metalinguagem

tem papel crucial na linguagem do professor, pois permite ao aluno criar suas representações mentais sobre o funcionamento da L-alvo e ativar sua cognição para a recepção da nova língua, o que contribuirá para o estabelecimento das bases dessa língua para que o usuário possa usá-la de forma eficiente e ser entendido. Ela insere-se no domínio de língua específico para o professor, uma vez que o conhecimento metalinguístico e seu uso na fala é o que diferencia um professor de outros falantes de LE. (FERNANDES, 2011, p. 40)

De acordo com Elder (1994) e Martins (2005), o domínio de uso da língua específico para o professor de LE é definido como: a) capacidade para usar a língua alvo tanto como meio quanto como objeto de ensino; b) a capacidade para modificar o insumo para que seja compreensível ao aprendiz; c) a capacidade para produzir insumo estruturado e adequado; d) a capacidade para falar sobre a forma e uso da língua por meio da própria língua (metalinguagem).

O domínio da língua alvo e o conhecimento de seu funcionamento juntamente com os conhecimentos teóricos constituem, então, o perfil do professor profissionalmente capacitado, diferenciando-o do falante de LE que pode utilizar essa língua para comunicar-se, mas não necessariamente para ensiná-la.

Walsh (2006), por sua vez, define a fala do professor em função de quatro características as quais acredita ser essencialmente responsabilidade do professor:

1) Controle dos padrões de comunicação: controle do tópico da conversação e da tomada de turnos - por meio da estrutura IRF (iniciação - resposta - feedback/retorno), de Sinclair e Coulthard (1975, 1992);

2) Uso de técnicas de elicitação: perguntas facilitadoras usadas para incentivo ou manutenção da participação dos alunos;

3) Reparo: correção de erros;

4) Modificação do discurso: simplificação lexical e sintática, redução da velocidade de fala, uso de gestos e expressões faciais. 
Esse autor desenvolveu um sistema de categorias de modos (modes) para a descrição da linguagem do professor em busca de uma representação dos múltiplos fatores que compõem o contexto de aula de LE. O modo é definido como "um microcontexto na sala de aula que tem um objetivo pedagógico claramente definido e características interacionais determinadas em grande parte pelo uso da língua pelo professor" (p. 63). Seu sistema pretende funcionar como um ponto de partida para estudos interpretativos da comunicação em sala de aula, além de ser um sistema descritivo que pode ser usado pelo professor para expandir seu entendimento dos processos interativos operantes em suas próprias aulas.

Os modos do sistema de Walsh (2006) são apresentados no seguinte quadro:

\begin{tabular}{|c|l|}
\hline Modo & \multicolumn{1}{c|}{ Objetivos pedagógicos } \\
\hline Gerencial & - Transmitir informação; \\
& - Organizar o ambiente físico; \\
& - Direcionar os alunos para o material; \\
& - Introduzir ou concluir uma atividade; \\
& - Mudar o agrupamento (trabalho em duplas, individual, \\
& - etc.) \\
\hline Material & - Oferecer prática linguística em torno do material; \\
& - Elicitar respostas em relação ao material; \\
& - Verificar e expor respostas; \\
& - Esclarecer quando necessário; \\
& - Avaliar contribuições. \\
\hline Habilidades e sistemas & - Possibilitar que os alunos produzam formas corretas; \\
& - Possibilitar que os alunos manipulem a língua-alvo; \\
& - Oferecer feedback corretivo; \\
& - Oferecer prática em sub-habilidades para os alunos; \\
& - Expor respostas corretas. \\
\hline Contexto de sala de aula & - Possibilitar que o aluno expresse-se claramente; \\
& - Estabelecer um contexto; \\
& - Promover fluência oral. \\
\hline
\end{tabular}

Quadro 01: Arcabouço de Walsh (traduzido de Walsh, 2006, p. 66)

Quanto à avaliação de proficiência oral dos professores de LE, podemos dizer que, depois do advento da abordagem comunicativa no ensino de línguas, sua importância aumentou, uma vez que trouxe à tona a questão do ensino de uma língua para fins comunicativos. No caso dos professores de PLE, não é diferente. Sua proficiência linguística deve ser constituída por um domínio geral do português e por um domínio específico da metalinguagem, conforme mencionado anteriormente nesta seção. Este último domínio é mostrado pelo profissional em sua atuação docente, seja ela uma situação real de sala de aula ou uma situação criada hipoteticamente, no caso de um item de um teste oral.

Discussões teóricas acerca da noção de proficiência oral estão presentes em diversos estudos na área de testes de LE, como em Teixeira da Silva (2000), Martins (2005), BaffiBonvino (2007) e Borges-Almeida (2009). A primeira faz uma discussão detalhada da relação entre "competência" e "proficiência" e busca uma definição para "fluência", diante da dificuldade em se conceituar tal termo. Martins focaliza a posição de Elder (1994, apud MARTINS, op. cit.), para a qual "a proficiência linguística do professor engloba tudo o que se espera que os usuários da língua utilizem em contextos formais e informais, além de uma gama de habilidades especificas" (MARTINS, op. cit., p. 40). Na busca por essa gama de habilidades específicas, a autora elenca as seguintes características como parte do domínio linguístico do professor de LE: 
1) a habilidade de usar a L-alvo tanto como meio quanto objeto da instrução;

2) a habilidade de modificar o insumo na L-alvo para que se torne um insumo compreensível aos aprendizes;

3) a capacidade de oferecer um insumo bem formado (em termos de precisão gramatical) para os aprendizes;

4) inteligibilidade - o professor apresentar uma pronúncia adequada de acordo com os padrões da L-alvo;

5) a capacidade de atrair a atenção do aprendiz às características da forma da L-alvo, por meio do uso da metalinguagem.

Segundo Fernandes (2011), é somente pelo desempenho do professor que sua habilidade linguística pode ser avaliada, o que reitera a importância da avaliação no processo de reflexão do professor sobre sua prática em sala de aula; no caso do que propõe esta pesquisa, contribui para a reflexão do professor de PLE em formação sobre sua habilidade e capacidade orais de explicar sua própria língua de maneira a alcançar os objetivos da aula planejada, de sanar as dúvidas de seus alunos e contribuir para sua aprendizagem.

\section{O EPPLE}

O Exame de Proficiência para Professores de Língua Estrangeira (EPPLE) (CONSOLO et. al., 2009, 2010) tem como propósito ser um exame específico que ofereça certificação para o professor de LE de acordo com seu nível de proficiência nas quatro habilidades linguísticas, além de oferecer bases para um possível efeito retroativo positivo nos cursos de Letras e nos critérios e procedimentos de avaliação da competência linguístico comunicativa do professor. A saber,

Durante o exame, o candidato deve desempenhar tarefas que se assemelham àquelas realizadas nos contextos de aulas de línguas estrangeiras. Por ser um exame para fins específicos, o EPPLE busca aferir a capacidade de uso da língua estrangeira, o que envolve conhecimentos de regras de comunicação e de formas socialmente aceitas, e conhecimentos sobre a língua, constituintes de uma competência metalinguística, o que configura o domínio específico de linguagem do professor de LE. (CONSOLO; TEIXEIRA DA SILVA, 2014, p. 74)

Para a consolidação do construto do EPPLE, de acordo com Consolo et. al. (2010), é necessário que: a) se aprimore a delimitação do domínio da linguagem do professor de LE, nos contextos de ensino de línguas no Brasil, e decorrente dessa delimitação, definirem-se os recortes linguísticos a serem considerados critérios de avaliação da proficiência linguística desse professor; b) se aprimore os descritores das faixas de proficiência criadas e revisadas para o exame, para que incluam, além de características linguísticas, tarefas a serem desempenhadas pelo professor de ILE por meio da linguagem; c) se especifique as tarefas que melhor se prestem a avaliar a proficiência linguística de professores no contexto de um exame de proficiência que atinja as quatro habilidades de uso da LE (compreensão e produção, escrita e oral), necessárias a esses profissionais.

No quadro 02, a seguir, são descritos os aspectos gerais do EPPLE que caracterizam seu formato. 
- Aplicado via computador, por sistema desenvolvido especialmente para o exame. O sistema funciona off-line, sendo necessário acesso à internet apenas para fazer download do programa e transmitir as respostas após a aplicação.

- Tem duração total de 120 minutos;

- É constituído por teste oral e teste escrito;

- Inclui tarefas integrativas, que acionam duas habilidades (ex. leitura e escrita / compreensão auditiva e produção oral);

- No teste oral, o candidato fala em um microfone. Suas respostas são gravadas e posteriormente enviadas para a plataforma do exame;

- Para cada tarefa, há um espaço único onde a resposta é digitada ou gravada em áudio;

- Pontuação - o escore do candidato é gerado com base nos cinco níveis da escala de proficiência, que vão de A a E, sendo A a nota mais alta e E, a nota mais baixa.

\section{Quadro 02: Descrição geral do formato do EPPLE}

O público-alvo do EPPLE consiste em professores de LE em formação e professores de LE atuantes no ensino fundamental e médio da escola regular, em universidades e/ou em escolas de idiomas. O exame é composto de dois testes: um teste oral (compreensão e produção oral) e um teste escrito (compreensão e produção escrita).

Em 2015, foi elaborada a terceira versão do EPPLE ${ }^{4}$, e sua criação do justifica-se pela necessidade de se estabelecerem os perfis adequados do professor de línguas no Brasil e também pela ausência de um exame específico para esse profissional na área de formação de professores.

\section{Metodologia de investigação}

O propósito maior deste estudo é sugerir conteúdos para itens de teste oral de PLE que buscam avaliar a proficiência do professor ao fazer uso de sua língua de docência para explicá-la, respeitando o conhecimento das regras de comunicação e das formas socialmente aceitas da língua portuguesa.

Desenvolveu-se, então, uma pesquisa de cunho qualitativo (ANDRÉ, 1995; BURNS, 1999), de natureza interpretativista (MOITA LOPES, 1994; DENZIN; LINCOLN, 2007) e como um estudo de caso (ANDRÉ, 2005; GIVEN, 2008) de cada contexto explorado.

Também se trata de uma pesquisa que envolve procedimentos quantitativos, pois o número de ocorrências encontradas é relevante para o desenvolvimento do trabalho. Evidencia-se que essa combinação de abordagens, quantitativa-qualitativa, pode gerar contribuições para pesquisas em ensino-aprendizagem de línguas, pois, esse tipo de pesquisa consegue auxiliar na análise e validação dos dados, uma vez que há o poder para mudança de perspectivas nas variáveis de interesse e para o auxílio de desenvolvimento de construtos teóricos ou relações entre eles. Além disso, de acordo com Wallace (1998), os dados quantitativos podem ajudar na reflexão dos critérios qualitativos e vice-versa.

Nesta pesquisa, como apenas a visão da pesquisadora será considerada, ela é considerada parte integrante do processo de conhecimento, já que é ela quem interpreta os fenômenos e lhes atribui significados a partir do seu ponto de vista. Isso faz com que esta investigação se oponha, então, àquelas de base etnográfica, pois não considera a visão da

\footnotetext{
${ }^{4}$ A primeira versão do EPPLE foi desenvolvida em caráter experimental para aplicação presencial. Uma amostra dessa versão está disponível no site www.epplebrasil.org
} 
realidade construída pelos demais participantes da pesquisa. Diante desse cenário, o presente trabalho se revela de natureza interpretativista, como Moita Lopes (1994) e Denzin e Lincoln (2007) definem, porque o observador não é neutro e objetivo, uma vez que ele tem uma posição histórica e se situa localmente como observador humano da condição humana.

\section{Contextos de pesquisa}

O corpus desta investigação foi composto a partir de dados coletados em dois ambientes que permeiam a área de PLE da UNESP/IBILCE. A predileção por esses dois contextos de pesquisa ao invés de um se justifica na busca pela ampliação do corpus, com o objetivo de dar maior confiabilidade aos resultados do trabalho. Também pelo fato de se tratar de dados coletados em contextos representativos da realidade do curso de Licenciatura em Letras da UNESP/IBILCE, isto é, um ambiente de formação de professores, um dos pilares deste trabalho.

O primeiro contexto de pesquisa explorado por esse estudo foi o Teletandem Institucional Integrado (doravante TTDii), que se originou do Projeto Teletandem Brasil: linguas estrangeiras para todos ${ }^{5}$ (TELLES, 2006).

Teletandem (TTD) é um contexto virtual, autônomo e telecolaborativo de interação ou contato intercultural online (TELLES, 2015a) e carrega em seu bojo a modalidade de tandem à distância. Seu objetivo é promover o ensino-aprendizagem de línguas estrangeiras por meio de encontros virtuais regulares entre pares de falantes de diferentes línguas que vivem em diferentes países (ARANHA; CAVALARI, 2014). TELLES (2006, 2009) explica que o TTD faz uso dos aspectos oral (ouvir e falar), escrito (ler e escrever) e paralinguísticos da línguaalvo. Tal contexto de ensino-aprendizagem de línguas é viabilizado pelo uso de aplicativos que dispõem de recursos multimodais. Os usuários interagem na língua alvo e em sua língua materna, em tempo real, utilizando recursos de voz, texto e imagens de aplicativos de tecnologia VOIP (Voice Over Internet Protocol), como o Skype e, mais recentemente, o Zoom. Durante as sessões de TTD, cada aprendiz pratica sua língua-alvo por metade do tempo da sessão, de modo colaborativo e ao mesmo tempo autônomo, uma vez que os parceiros também negociam suas necessidades linguísticas e como gostariam de abordá-las durante a interação. Além do foco na comunicação autêntica na língua-alvo, os interagentes também refletem sobre aspectos linguísticos e culturais das LEs que se dedicam a aprender (BRAMMETS \& CALVERT, 2003).

Vale ser destacado que, mesmo que a prática de teletandem não vise à formação de professor, já que não só alunos dos cursos de licenciatura participam da atividade, mas também estudantes de todos os cursos da UNESP, esta investigação tem como foco interações de teletandem realizadas na grade curricular da formação inicial de estudantes do curso de Licenciatura em Letras da UNESP/IBILCE, por isso, aqui, pode ser denominado um ambiente de formação de professores.

As interações das seções de TDDii analisadas nesse estudo foram gravadas em áudio e vídeo no decorrer das aulas de língua inglesa de uma turma de alunos do quarto ano de Licenciatura em Letras (habilitação português/inglês) do IBILCE/NESP, que aconteceram por um período aproximado de dois meses no segundo semestre de 2014. Os alunos brasileiros em questão fizeram parceria com alunos de uma universidade estadunidense, e a análise da metalinguagem do professor de PLE em formação proposta partiu de dados coletados apenas na parte em português da interação entre as duplas participantes.

A parceria entre as duplas interagentes no TTDii se estabelece da seguinte maneira: a interação tem cinquenta minutos de duração, em que cada um faz o papel de aluno por metade

\footnotetext{
${ }^{5}$ Maiores informações no site do projeto: www.teletandembrasil.org
} 
desse tempo, falando e praticando a língua do outro parceiro. Passadas os primeiros vinte e cinco minutos, eles trocam de papéis e de línguas. Os parceiros interagentes se encontram virtualmente por meio de um recurso de comunicação síncrona, como o Skype, por exemplo, e se comprometem a gerenciar a própria aprendizagem, assim como apoiar a aprendizagem do parceiro para que ambos se beneficiem.

A pesquisadora ouviu e assistiu à parte em português de todas as gravações de interações dos alunos que autorizaram a utilização de seus dados para a pesquisa em TTD e, a partir desse primeiro contato, escolheu o material coletado de apenas um aluno, cujas seções de interação oral ( $\mathrm{SInO})$ julgou serem mais ricas em possibilidades de análise a respeito da metalinguagem. O par escolhido foi formado pelo usuário 13 (denominação de acordo com a conta de Skype providenciada pelo laboratório Teletandem) e sua parceira estadunidense, contando com seis SInO, cinco gravadas em áudio e vídeo, e uma sessão gravada apenas em áudio.

Em termos gerais, a escolha do par se justifica, pois: (a) faz parte de um grupo em que a prática de TTD está integrada às aulas de língua estrangeira de um curso de Licenciatura em Letras; (b) apresenta assinados os termos de consentimento de uso dos dados para pesquisa pelas participantes; e (c) os seus dados foram gravados com aproveitamento.

O segundo contexto de pesquisa, por sua vez, consiste em aulas ministradas presencialmente por duas professoras colaboradoras, em uma turma iniciante de estrangeiros, denominada PLE I, criada a partir do projeto de extensão "Português Língua Estrangeira (PLE)", oferecido pelo IBILCE/UNESP, e coordenado pela Profa. Dra. Marta Lúcia Cabrera Kfouri Kaneoya, do Departamento de Educação do mesmo instituto ${ }^{6}$.

O projeto PLE, criado em 2012, tem por público-alvo não somente estudantes da UNESP de São José do Rio Preto em situação de intercâmbio no Brasil, mas também estrangeiros de diferentes nacionalidades, residentes no município e região onde a Universidade está inserida, e que desejam ou têm necessidades de conhecer/ampliar conhecimentos sobre/na língua portuguesa e cultura brasileira, além de difundi-los internacionalmente. Segundo Kfouri-Kaneoya (2013), trata-se de um contexto em que se ensina PLE, ao mesmo tempo em que se forma o professor para isso, uma vez que o professor de PLE desenvolve, na verdade, uma consciência metalinguística, proporcionada, sobretudo, pelo fato de ter de pensar mais sobre sua língua materna para ensiná-la a aprendizes de línguas diversas.

A turma presencial de PLE I cujas aulas estão sendo analisadas teve início no primeiro semestre de 2016, mais especificamente em 07 de abril. O curso, com carga horária total de 60 horas, se dividiu em dois encontros semanais de 1 hora e 40 minutos realizados às quartas e às quintas-feiras, das $19 \mathrm{~h}$ às $20 \mathrm{~h} 40$.

A pesquisadora coletou dados de 04 encontros, totalizando 08 horas/aula. A observação das aulas ocorreu a partir da quinta aula ministrada até a oitava, acontecendo mais especificamente nos dia 27 e 28 de abril e 04 e 05 de maio.

A turma de alunos de PLE I cujos dados foram coletados é composta somente de 05 alunos de nacionalidades e ocupações diferentes. Trata-se de 03 alunos chineses, que se mudaram para o Brasil por conta de seu trabalho em uma empresa multinacional e, por isso, viram-se diante da necessidade imediata de aprender português; 01 aluna canadense, que se mudou para o Brasil por ter se casado com um brasileiro; e 01 aluna síria, que precisou abandonar seu país e procurar refúgio em terras brasileiras devido à violenta situação de guerra civil e total destruição que a Síria enfrenta atualmente.

As aulas foram gravadas em áudio, transcritas e analisadas pela pesquisadora para os devidos propósitos deste estudo. Nesse tipo de pesquisa, segundo Oliveira (2007), essas fontes são consideradas primárias, pois ainda não foram manejadas cientificamente, ou

\footnotetext{
${ }^{6}$ Maiores informações no site do projeto: pleibilce.wix.com/curso
} 
melhor, o pesquisador será quem as analisará, não tendo, ainda, portanto, o domínio público de uma pesquisa bibliográfica, por exemplo.

\section{Procedimento de análise dos dados}

Os procedimentos de análise baseiam-se, a partir da transcrição verbatim, em Marcuschi (2003) e Gonçalves e Tenani (2008): i) no caso dos dados do TTDii, dos vídeos da parte em que as participantes interagem em língua portuguesa; ii) das gravações em áudios das aulas presenciais de língua portuguesa da turma PLE I do Projeto PLE. Tais transcrições foram realizadas por meio do programa Transana ${ }^{7}$.

A partir do material coletado para a formulação do corpus, o foco de descrição e análise é a metalinguagem do professor de PLE em formação, isto é, foram considerados apenas os trechos de explicação e/ou esclarecimento linguístico sobre a língua portuguesa. A investigação se baseia em:

a) delimitar se há e quais são as ocorrências de maior frequência em relação às explicações feitas pelos professores em formação sobre sua língua materna em ambos os contextos;

b) comparar as ocorrências encontradas em ambos os contextos, observando suas características em comum, que constituem dúvidas dos aprendizes de PLE;

c) e em como é feito o uso da metalinguagem nessas explicações.

Uma vez que, como afirma Elder (2001), os professores de línguas necessitam de habilidades linguísticas específicas que incluam o domínio da terminologia e da metalinguagem dos conteúdos específicos a serem ensinados, a competência discursiva para o tratamento desses conteúdos em sala de aula está sendo considerada como foco primordial da análise dos dados, o que incluem estratégias de simplificação de áreas especializadas do conhecimento para facilitar a compreensão por parte dos alunos. O ensino de PLE exige flexibilidade do professor no uso de estratégias de comunicação específicas para esse contexto, tais como repetição, substituição, explicação, exemplificação e checagem de compreensão (MITCHELL, 1988). Esses aspectos compõem, entre outros, a competência linguístico-comunicativa (CLC) do professor de línguas.

Os fundamentos teóricos postulados por Walsh (2006), mais especificamente os modos de Habilidades e sistemas e Contexto de sala de aula, guiaram a discussão dos dados desta investigação, devido ao caráter descritivo e prático do arcabouço de objetivos pedagógicos criado por esse autor. Os demais posicionamentos teóricos auxiliam-nos no entendimento das particularidades da comunicação em contexto de ensino-aprendizagem, tanto em sala de aula como em contextos online e telecolaborativos, como o TTDii (a ser explorado mais detalhadamente no próximo capítulo deste trabalho), e do domínio de linguagem do PEF-PLE nesses momentos de interação.

\section{Resultados preliminares}

Até o presente momento desta pesquisa (dezembro de 2016), os dados coletados do TTDii foram os mais explorados. A seguir, serão apresentados alguns excertos que evidenciam algumas características da fala de professor que foram discutidas até o momento neste trabalho. Nos trechos a seguir, B representa a aluna brasileira, aqui considerada como uma professora de português língua estrangeira em formação, e A representa sua parceira nas sessões de interação oral no TTDii:

\footnotetext{
${ }^{7}$ Mais informações em http://www.transana.org/
} 
B: é::... então, é::... é, é onde o emprego, o trabalho?

A: hum?

B: ONDE é o trabalho? em que lugar? ... o trabalho que você conseguiu, o emprego

A: oh s/... onde eu?

B: é/ onde você vai trabalhar? é uma empresa?

A: oh:: sim! ((risos)) sim, é:: uma empresa que:: ah::... planea ah:: eventos? ((expressa dúvida quanto às últimas duas palavras ditas por ela por isso o tom de pergunta)) para ah:: pa qualquer coisa como festas ou reuniões ou coisas assim

B: entendi

A: então eu vou ah:: limpar depois dos eventos ((risos) então, penso que vai s/vai ser muito inte/ ah vai s/ vai ser muito interessante? ou estar? ser ou estar?

B: ser

A: ser. muito interessante porque eu posso ir a diferentes lugares para os eventos ah:: ciudades diferentes e coisas assim

B: entendi

Excerto 01 - Conversando sobre o novo emprego da parceira estadunidense

O primeiro trecho grifado em negrito se refere a uma explicação em que PEF (professora em formação) procura enfatizar a palavra "onde" e a palavra "trabalho", para que sua parceira entenda sua pergunta. Em seguida, ela refaz a pergunta de maneira diferente, uma estratégia para que a compreensão de sua parceira seja facilitada, demonstrando habilidade de modificar o insumo na língua-alvo para que se torne um insumo compreensível aos aprendizes (Martins, 2005);

A aprendiz de PLE, por sua vez, no trecho sublinhado, utiliza-se de pergunta direta para expressar sua dúvida ("vai ser muito interessante? Ou estar? Ser ou estar?"), obtendo uma resposta direta da PEF: "ser".

B: ah, é ontem eu tava pensando em que assuntos a gente podia conversar:: porque eu fico sempre tentando arranjar assuntos para conversar, a gente fa/ é, o professor fala pra gente lev/anotar alguma coisa que a gente tenha curiosidade, é, sobre a cultura de vocês, enfim, se tem alguma $\mathrm{co} / \mathrm{mas}$ você, tem alguma curiosidade sobre o Brasil, alguma coisa que você não entende, cê queria saber como é que é...?

A: hum... tenho que pensar porque... ah::... hum::... não sei porque...

$\mathrm{B}$ : mas se voc/se você quiser anotar depois algumas dúvidas pra trazer dep/ah em uma próxima interação

A: $\operatorname{sim}$

Excerto 02 - Questionamento sobre os interesses de aprendizagem da aprendiz de PLE

No excerto anterior, podemos observar, em sua primeira fala, uma preocupação da PEF em relação ao conteúdo da interação: ela deixa claro que procura buscar temas que agradem sua parceira, também perguntando quais são os seus interesses de aprendizagem em relação à LP. Em seguida, no trecho em negrito, a PEF também sugere a sua parceira sobre como proceder em relação às suas dúvidas: "/se você quiser anotar depois algumas dúvidas pra trazer dep/ah em uma próxima interação", evidenciando uma linguagem típica de professor, uma orientação de estratégia de aprendizagem. 
A: penso que muitos pessoas na universidade, aqui eu sei muitos, muitos cristianos porque eu sou cristiano, então... eu

B: AH, é

A: eu sou cris...?

\section{B: CRIST $\tilde{A}$}

A: cristã

B: sim

A: ok, cristã... então eu sou cristã, então eu sei muitos crista...

B: cristão/cristãos

A: cristãos, e:: mas eu sei muitos ateus também

B: ah, no caso, é, se você:: tem, é/é porque a tradução fica estranha, que $K N O W$ também quer dizer "sei" em português, mas no caso é "eu CONHEÇO"

A: eu conheço

B: muitos...

A: muitos ateus, sim, é claro, eu...

B: é que também poder ser "eu sei"... a gente confunde

A: e:: é mais correto para dizer "conheço", sim...

\section{Excerto 03 - Conversando sobre religião}

No trecho destacado acima, podemos observar o uso de um tom mais enérgico marcado na pronúncia da palavra "cristã" por parte da PEF, que busca enfatizar, para a aprendiz de PLE, a maneira correta de se pronunciar a palavra. Questões de pronúncia são bastante recorrentes nos ambientes de aprendizagem de LE.

Também podemos observar, em seguida, a explicação que a PEF faz a respeito de um emprego verbal inadequado feito por parte da aprendiz de PLE, que traduz o verbo "know" para "sei", num contexto em que o mais apropriado seria a forma verbal "conheço".

$\mathrm{Na}$ última sentença destacada em negrito, podemos observar um atenuante em relação à fala da PEF, comentando ser normal que as pessoas confundam o contexto de uso desses dois verbos no português.

\section{Encaminhamentos}

As próximas etapas desta investigação consistem na finalização da análise e discussão dos dados, comparando a metalinguagem do professor de PLE em formação nos dois contextos de pesquisa aqui explorados. As ocorrências encontradas serão tabeladas e separadas por categorias que explorem as funções comunicativas pertinentes à fala do professor, de modo geral. Também deverão ser categorizadas por elementos mais específicos, como explicações sobre a estrutura e o funcionamento da língua, por exemplo.

Também serão exploradas as técnicas de elaboração de itens de testes orais e o que se espera que o candidato responda, nesses itens. Por exemplo: um item pode ser montado a partir de uma pergunta típica de um aprendiz de PLE, para a qual existe, nos dados, uma resposta de professor que a) pelo contexto, se percebe que o aluno entendeu e que essa fala de professor pode ter contribuído para a aprendizagem de PLE, ou que b) seja uma resposta, uma fala, que nós, usuários altamente proficientes em português, consideramos correta e adequada para o contexto dos dados. Estes são critérios viáveis para uma espécie de "gabarito" dos itens de teste oral a ser propostos. 
Por fim, as ocorrências mais recorrentes de questões linguísticas por parte dos aprendizes de PLE e a maneira como os professores de PLE em formação se manifestam em relação a essas questões servirão de base para a criação de itens de teste oral que procuram avaliar a proficiência oral do professor de PLE no EPPLE, alcançando, desta maneira, o objetivo principal do presente estudo.

\section{Referências}

ALMEIDA FILHO, J. C. P. Dimensões comunicativas no ensino de línguas. Campinas: Pontes, 1993.

(Org.) O professor de língua estrangeira em formação. Campinas: Pontes, 1999.

O professor de língua(s) profissional, reflexivo e comunicacional. Horizontes de Linguística Aplicada, Brasília, vol. 3, n. 1, p. 07-19, 2004

O Português como língua não-materna: Concepções e contexto de ensino. Acervo digital do Museu da Língua Portuguesa. 2005. Acessado em 20/02/2016 <http://www.museulinguaportuguesa.org.br/files/mlp/texto_4.pdf>

Maneiras de credenciar-se na área de ensino de português a falantes de outras línguas. J.C.P. de Almeida Filho e M. J. C. Cunha (Org.). Projetos iniciais em português para falantes de outras línguas. Campinas, Pontes: p. 33-37, 2007.

ANDRÉ, M. E. D. A. de. Etnografia da prática escolar. Campinas: Papirus, 1995.

ARANHA, S., CAVALARI, S. M. S. A trajetória do projeto Teletandem Brasil: da modalidade institucional não-integrada à institucional integrada. The ESPecialist, vol. $35, \mathrm{n}^{\circ}$ 2, p. 183-201, 2014.

BAGHIN-SPINELLI, D. C. M. Ser professor (brasileiro) de língua inglesa: um estudo de processos identitários nas práticas de ensino. Tese de Doutorado. Campinas: Unicamp. 2002.

BASSO, E. A. A construção social das competências necessárias ao professor de língua estrangeira: entre o real e o ideal um curso de Letras em estudo. Tese de Doutorado. Campinas: UNICAMP, 2001.

BRAMMERTS, H., CALVERT, M. Learning by communicating in tandem. In: LEWIS, T., WALKER, L. (EDS.) Autonomous Language Learning In-tandem. Sheffield, UK: Academy Eletronic Publications, pp. 45-60, 2003.

BROCCO, A. S. A gramática em contexto teletandem e em livros didáticos de português como língua estrangeira. 2009. 249 f. Dissertação de Mestrado. Instituto de Biociências, Letras e Ciências Exatas, Universidade Estadual Paulista, São José do Rio preto, 2009.

BURNS, A. Collaborative Research for English Language Teachers. Cambridge: Cambridge University Press, 1999.

BUSNARDI, B. Precisão e complexidade gramatical na avaliação da proficiência oral do (futuro) professor de inglês como língua estrangeira. Dissertação de Mestrado. São José do Rio Preto, SP: IBILCE/UNESP, 2012. 
CONSOLO, D. A.; TEIXEIRA DA SILVA, V. L (Org.) Em defesa de uma formação linguística de qualidade para professores de línguas estrangeiras: o exame Epple. São José do Rio Preto: RNHLA, 2014.

CONSOLO, D. A. Uma reflexão sobre o falante nativo como paradigma no ensino/aprendizagem de línguas estrangeiras. In S. C. KURTZ \& I. MOZZILLO (Org.). Cultura e Diversidade na Sala de Aula de Língua Estrangeira. Pelotas, Editora da UFPEL, 2008, p.82-97.

A competência oral de professores de língua estrangeira: a relação teoria-prática no contexto brasileiro. In: CONSOLO, D.A.; TEIXEIRA DA SILVA, V. L. T (Org.). Olhares sobre competências do professor de língua estrangeira: da formação ao desempenho profissional. São José do Rio Preto: HN, 2007.

On a (re)definition of oral language proficiency for EFL teachers: perspectives and contributions from current research. Melbourne Papers in Language Testing, vol. 1, 2006, p. 128.

A construção de um instrumento de avaliação da proficiência oral do professor de língua estrangeira. Trabalhos em Linguística Aplicada, vol. 43, n. 2, 2004, p. 265-286.

Competência linguístico-comunicativa: (re)definindo o perfil do professor de língua estrangeira. Anais do VI Congresso Brasileiro de Linguística Aplicada. Belo Horizonte: UFMG, 2002 (CD-ROM).

Classroom Discourse in Language Teaching: a study of oral interaction in EFL lessons in Brazil. Tese de Doutorado. Universidade de Reading, Inglaterra, 1996.

CONSOLO, D.A.; TEIXEIRA DA SILVA, V. L (Org.). Olhares sobre competências do professor de língua estrangeira: da formação ao desempenho profissional. São José do Rio Preto: HN, 2007.

CRISTOVÃO, V. L. L. Por relações colaborativas entre universidades e escolas. In: CRISTOVÃO, V. L. L.; GIMENEZ, T. (Org.). ENFOPLI: construindo uma comunidade de formadores de professores de inglês. Londrina: Artgraf, 2005.

DENZIN, N. K.; LINCOLN, Y. S. Planejamento da pesquisa qualitativa: teorias e abordagens. Tradução Sandra Regina Netz. Porto Alegre, RS: Artmed, 2007.

ELDER, C. Assessing the Language Proficiency of Teachers: Are There Any Border Controls? Language Testing, vol. 18, no2, p. 149-170, 2001.

Performance Testing as a benchmark for LOTE Teacher Education. Melbourne Papers in Language Testing, vol. 3, n. 1, 1994, p. 1-25.

ERICKSON, Frederick. Qualitative Methods in Research on Teaching. In: WITTROCK, Merlin C. Handbook of Research on Teaching. 3. ed. New York: Macmillan, 1986. p. 119161.

FERNANDES, A. M. A metalinguagem e a precisão gramatical na proficiência oral de duas professoras de inglês como língua estrangeira. Dissertação de Mestrado. São José do Rio Preto, SP: IBILCE/UNESP, 2011. 
FURTOSO, V. A. B. Desempenho oral em português para falantes de outras línguas: da avaliação à aprendizagem de línguas estrangeiras em contexto online. Tese de Doutorado. São José do Rio Preto, SP: IBILCE/UNESP, 2011.

GIMENEZ, T. (Org.) Trajetórias na formação de professores de línguas. Londrina: Editora da UEL, 2002.

(Org.) Ensino e aprendendo inglês na universidade: formação de professores em tempo de mudança. Londrina: ABRAPUI, 2003.

GIVEN, L. M. (Ed.) The SAGE Encyclopedia of Qualitative Research Methods, v. 1 and 2. Los Angeles: SAGE Publications, 2008.

GONÇALVES, S. C. L., TENANI, L. E. Problemas teórico-metodológicos na elaboração de um sistema de transcrição de dados interacionais: o caso do projeto ALIP (Amostra Lingüística do Interior Paulista). Gragoatá (UFF), v.25, p.12 - 28, 2008.

HUGHES, G. S. A handbook of classroom English. Oxford: OUP, 1981.

KFOURI-KANEOYA, M. L. C. O ensino de PLE em um contexto universitário: implicações para a formação do discurso e para a formação do professor. Revista Mosaico, São José do Rio Preto, SP: IBILCE/UNESP, v. 12, 2013, p. 339-352.

McNAMARA, T. Language testing. Oxford: Oxford University Press, 2000.

MARCUSCHI, L. A. Produção textual, análise de gêneros e compreensão. São Paulo: Parábola Editorial, 2008.

MARGONARI, D. M.; SILVA, A. Re/estruturações no processo de formação profissional de professores iniciantes de língua inglesa. Signum - Estudos da Linguagem, Londrina, vol.1, p. 127-142, 2007.

MARTINS, T. H. B. Subsídios para a elaboração de um exame de proficiência para professores de inglês. Dissertação de Mestrado. Campinas: UNICAMP, 2005.

MITCHELL, R. Communicative language teaching in practice. London: CILT, 1988.

OLIVEIRA, M. M. Como fazer pesquisa qualitativa. Petrópolis: Vozes, 2007.

TELLES, J.A. Teletandem and performativity. Revista Brasileira de Linguística Aplicada, 15(1), p. 1-30, 2015. Disponível em http://dx.doi.org/10.1590/1984-639820155536. Acesso em $18 / 04 / 2016$

TELLES, J. A. Do we really need a webcam? - The uses that foreign language students make out of webcam images during teletandem sessions. In: Letras \& Letras. 25 (2) p. 65-79, 2009.

em http://www.seer.ufu.br/index.php/letraseletras/article/viewFile/25529/14135.

Acesso em Acesso em 18/04/2016.

TEIXEIRA DA SILVA, V. L. Fluência Oral: Imaginário, Construto e Realidade num Curso de Letras/LE. Tese de Doutorado. Campinas: UscaraNICAMP, 2000. 
VIEIRA-ABRAHÃO, M. H. Conflitos e incertezas na renovação da prática de sala de aula do professor de língua estrangeira: um estudo de caso. Tese de Doutorado. Campinas: UNICAMP, 1996.

A formação do professor de línguas: passado, presente e futuro. In: Kleber Aparecido da Silva. (Org.). Ensinar e aprender línguas na contemporaneidade: linhas e entrelinhas. 1 ed. Campinas: Pontes Editores, 2010, v. 1, p. 225-234.

A formação acadêmica e a iniciação profissional do professor de língua estrangeira. Trabalhos em Linguística Aplicada, UNICAMP-CAMPINAS, v. 37, p. 61-81, 2001.

A formação inicial e o desenvolvimento profissional do professor de línguas estrangeiras: práticas e pesquisas. Horizontes, Brasília, v. 5, n. 2, p. 8-23, 2006.

VIEIRA-ABRAHÃO, M. H.; GIL, G. (Org.). Educação de Professores de Línguas: os desafios do formador. 1. ed. Campinas: Pontes Editores. v. 1000. p. 358, 2008.

WALSH, S. Investigating Classroom Discourse. New York: Routledge, 2006. 